\title{
Effect of Knitted Structures and Yarn Count on the Properties of Weft Knitted Fabrics
}

\author{
Zubair Bin Sayed1*, Tarikul Islam², Nazif Hasan Chawdhury¹, Mafzal Ahmed ${ }^{1}$ \\ ${ }^{1}$ Department of Textile Engineering, Port City International University, Chittagong, Bangladesh \\ ${ }^{2}$ Department of Apparel Manufacture and Technology, BGMEA University of Fashion and Technology, Dhaka, Bangladesh \\ Email: *zubinsayeed@gmail.com, matarikul.islam2014@gmail.com, nazif92bd@gmail.com, mafzalahmed54@gmail.com
}

How to cite this paper: Sayed, Z.B., Islam, T., Chawdhury, N.H. and Ahmed, M. (2018) Effect of Knitted Structures and Yarn Count on the Properties of Weft Knitted Fabrics. Journal of Textile Science and Technology, 4, 67-77.

https://doi.org/10.4236/jtst.2018.42004

Received: March 8, 2018

Accepted: May 8, 2018

Published: May 11, 2018

Copyright $\odot 2018$ by authors and Scientific Research Publishing Inc. This work is licensed under the Creative Commons Attribution International License (CC BY 4.0).

http://creativecommons.org/licenses/by/4.0/

\begin{abstract}
This paper is focused on change in shrinkage, GSM, Wales per Inch and Course per Inch due to structure and count variation and state variation. This work was carried out with 12 samples of single jersey, single lacoste and weft lock knit fabrics of different counts which were scoured with $\mathrm{NaOH}$. After pretreatment process the samples were tested for widthwise shrinkage, width, GSM, Wales per Inch and Course per Inch and compared between different states like grey state and finished state. The result obtained in this research indicated that physical properties like structures with tuck stitch possess higher value of widthwise shrinkage, width, GSM and Wales per Inch and Course per Inch value lowers prominently in those structures having float or miss stitches. In both cases i.e. grey state and RFD state values of those properties are high in coarser yarn and low in finer yarn. During project knitted fabrics specification along with machine specification and major factors which are necessary to calculate different types of variation and variables on which the whole fabric construction depends were managed to watch carefully. Main efforts were to develop a dependable way so that the resulting fabric specifications with required configuration can be easily visualized and be forecasted. A great emphasization was provided to the adjustable points on which fabric GSM, stitch length, fabric width and shrinkage percentage directly or indirectly depends.
\end{abstract}

\section{Keywords}

Course per Inch, Count, GSM, Shrinkage, Wales per Inch, Weft Knitting

\section{Introduction}

Fabric is manufactured assembly of fibers and yarn that has substantial surface area in relation to its thickness and sufficient cohesion to give the assembly use- 
ful mechanical strength. Fabrics are most commonly woven or knitted but the term includes assemblies produced by felting, lace making, net making, non-woven processes and tufting. This project is basically on knitted fabric specification and machine which are related to knitted fabric production.

There was problem in our industries to produce knitted fabric of required GSM. Other specifications like fabric width, fabric thickness, fabric shrinkage \% are generally maintained in industries by previous data sheet. For this reason problem arises when any order comes which does not have a historical document.

Target of this project is to find out the easy process to get decision about yarn count selection, loop length selection, machine diameter selection and machine gauge selection.

This paper will be able to provide decision about yarn count, loop length, machine gauge and machine diameter for single jersey, single lacoste, polo pique and weft lock knit fabric.

Manufacturing of knitted fabrics involves intermeshing of yarn loops where one loop is drawn through another loop to form a stitch. Since the last few years knitted fabrics are used in manufacturing of fashion garments and even it has the potential in the formal wear segments also. Shrinkage is one of the most serious problems of the fabric faults. Especially, it is obtained in single jersey knitted fabric. Because of difference of both sides of single jersey knit fabric \& side (Face or back) of the single jersey always tends to create curling [1].

Thus, shrinkage is formed in single jersey mostly, where the other fabric is not so affected greatly as compared with it. Shrinkage on fabric creates, stitching problem which resulting seam pucker problem.

Human feels uncomfortable due to wear of shrined cloth. Apart from this, spirality is another serious problem for single jersey knitted fabrics due to their asymmetrical loop formation [2]. Specification methods of knitted fabrics, usually, include loop density, width of the fabric, weight per square meter and the loop length [3].

Flexibility exists at the various stages of wet processing in terms of process machinery and methods followed by calendaring or compacting which is often, the final operation prior to the packaging step. The level of shrinkage control needed, composition of yarn (100\% cotton, blends) and type of chemicals applied to the fabric decide the final process, i.e., whether calendaring or compacting [4].

Variable compactors are used to achieve specific stitch count and wet compacting is also carried out in certain cases [5]. Knitting is a technique for producing a two dimensional fabric made from a one-dimensional yarn or thread. It is the method of creating fabric by transforming continuous strand of yarn into series of inters looping loops, each row of such loops hanging from the one immediately preceding it [6]. The basic element of a knit fabric structure is the loop intermeshed with the loops adjacent to it on both side and above and below it. Knitted fabrics are divided into two major groups, weft \& warp knitted fabric 
[7]. Weft knitted fabrics can be produced in circular or flat knitting machine. The primary knitting elements of circular knitting machines are needle, cam, and sinker. The rising demand on knitted garments all over the world motivate the researcher to research about various knitted fabric, production processes, developing new structures. Knitting machines comprise a needle holder that supports a plurality of needles, which are arranged side by side and can be actuated with an alternating motion along their axis with respect to the needle holder in order to form knitting. Single cylinder circular knitting machines are generally provided, at the upper end of the needle cylinder, with an annular element which is fixed integrally around the upper end of the needle cylinder and is provided with radial cuts, inside each of which a sinker is arranged, and this radial cuts are angularly offset around the needle cylinder axis with respect to the needle sliding channels so that each sinker is located between two contiguous needles [8]. In the circular knitting machine with a great number of knitting needles, when the number of needle increases, the distances between the needles or sinkers have to be shrunk. Different count yarns produce different knit fabric [9]. The properties of knit fabric are changing with change of count of the yarn by keeping the parameters of knitting machine (dia, gauge, stitch length) same in every case. Properties of knitted fabric like GSM, CPI, WPI, shrinkage (length \& width wise), spirality etc. are showing different value in different count yarn .In this paper changing of values with the changing of count of yarn were observed. Here, four different counts of yarns were used.

\section{Materials \& Methods}

\subsection{Materials}

In this project work, the following materials are used to evaluate the properties of weft knitted fabrics. This work is done in Asha Knit Composite Ltd. Konabari, Gazipur, Bangladesh.

- Single Jersey Fabric (26 Ne).

- Single Jersey Fabric (30 Ne).

- Single Lacoste Fabric (26 Ne).

- Single Lacoste Fabric $(30 \mathrm{Ne})$.

- Weft Lock Knit Fabric $(26 \mathrm{Ne})$.

- Weft Lock Knit Fabric (30 Ne).

\subsection{Methods}

\subsubsection{Yarn Selection}

As per the experiment the variation of properties of knitted fabric, different count of yarn such as 24/1,26/1 Ne were used for our experiment to produce three different weft knitted structures like-Single Jersey, Single Lacoste \& Weft Lock Knit.

\subsubsection{Machine}

Knitting machine (JIUNN LONG, TAIWAN) with 34" \& 30" diameter \& 24 
gauge have been used. And every experiment stitch length has kept individually $2.75,2.85,2.85 \mathrm{~mm}$. After producing grey fabric scouring was performed by FONGS Machine, China. A Washing machine was used for shrinkage test.

\subsubsection{Recipe Selection (Scouring)}

All Knitted fabrics were scoured in IR dyeing machine. For scouring, Jinterge Eco KS90 is used as detergent, Jinterge Eco $114 \mathrm{Fe}$ is used as sequestering agent and Jintex $2 \mathrm{UD}$ is used as demineralizing agent. The Liquor ratio was 1:50 and the temperature for scouring was $90^{\circ} \mathrm{C}$ to $95^{\circ} \mathrm{C}$ (Table 1 ).

\subsubsection{Fabric Relaxation}

Knit fabric has a special property called shrinkage. After the production knit fabric tends to shrink. For this fabric has to undergo a standard condition for complete relaxation. The fabrics had kept at $27^{\circ} \mathrm{C}$ temperature \& $65 \%$ relative humidity at our knitting lab.

\subsubsection{Equipment Selection}

1) Counting Glass.

2) Electronic Balance.

3) GSM Cutter.

\subsubsection{Determination of WPI}

After relaxation \& conditioning of knit fabric samples, the numbers of wales in a 1 " length of fabric were determined at five different places on every sample with a magnifying glass, and the average values were calculated of $26 \mathrm{~s}$ and $30 \mathrm{~s}$ carded yarn at both grey and scoured state for all three structures-Single Jersey, Single Lacoste \& Weft Lock Knit.

\subsubsection{Determination of CPI}

After relaxation \& conditioning of knit fabric samples, The numbers of courses in a " 1 " length of fabric were determined at five different places on every sample with a magnifying glass, and the average values were calculated of $26 \mathrm{~s}$ and $30 \mathrm{~s}$ carded yarn at both grey and scoured state for all three structures-Single Jersey, Single Lacoste \& Weft Lock Knit.

\subsubsection{Determination of Fabric Width}

After relaxation \& conditioning, the width of the fabric was measured by measuring tape, for different samples [10].

\subsubsection{Determination of Fabric Weight (GSM)}

After relaxation \& conditioning of knit fabric samples, GSM of samples were tested by taking test samples with the help of GSM cutter \& weighting balance (electronic) [11].

\subsubsection{Determination of Fabric Shrinkage}

The sample was laid on a flat horizontal surface, removing wrinkles without stretching. Then samples were cut into $45 \mathrm{~cm} \times 45 \mathrm{~cm}$ centrally so that the edge 
Table 1. Standard recipe for scouring.

\begin{tabular}{cc}
\hline Fabric Weight & $\mathrm{X} \mathrm{gm}$ \\
Water & $\mathrm{Y} \mathrm{ml}$ \\
Wetting Agent & $1 \mathrm{~g} / 1$ \\
Sequestering Agent & $1 \mathrm{~g} / 1$ \\
$\mathrm{NaOH}$ & $3 \mathrm{~g} / 1$ \\
$\mathrm{Na}_{2} \mathrm{CO}_{3}$ & $1 \mathrm{~g} / 1$ \\
Detergent & $1 \mathrm{~g} / 1$ \\
$\mathrm{M}: \mathrm{L}$ & $1: 50$ \\
Time & $1.5 \mathrm{Hr}$ \\
$\mathrm{pH}$ & $10.5-11$ \\
Temperature & $90^{\circ} \mathrm{C}-95^{\circ} \mathrm{C}$ \\
\hline
\end{tabular}

follows a wale line. Then $25 \mathrm{~cm} \times 25 \mathrm{~cm}$ area was marked in each sample the samples were put in the washing machine and continued washing for $45 \mathrm{mi}$ nutes. After washing completed, the fabrics are dried at room temperature At last all the measurements were taken and shrinkage $\%$ is tabulated;

$$
\text { Shrinkage } \%=\frac{a-b}{a} \times 100
$$

where, $a=$ Distance between two ends before wash,

$b=$ Distance between two ends after wash.

This operation was performed according to IS 139 and BS 1051 method [12].

\section{Results and Discussion}

\subsection{Comparison among Wales per Inch of the Structures}

From Figure 1 it is clear that, Weft Lock knit structure has much more WPI and Single Lacoste has the minimum. Because the structure with tuck stitch is wider than knit stitches and the loop shape has a wider base at stitches, that's why Single Lacoste has the minimum WPI. On the other hand float stitch makes the fabric narrower as there is no looped configuration.

In case of RFD fabrics, due to shrinkage WPI values increase.

From Figure 2 it is observed that, the WPI value of the fabric made of $30 \mathrm{~s} \mathrm{Ne}$ (both states) follows the previous sequence. But the values increase due to finer yarn.

\subsection{Comparison among Courses per Inch of the Structures}

From Figure 3 it is seen that, Weft Lock Knit structure has maximum CPI and Single Jersey has the minimum. The reason behind that miss loop has minimum height so maximum courses can be accumulated per unit space in case of Weft Lock Knit fabric. But the height of knit loop is maximum in case of Single Jersey fabric so minimum loops can be accommodated. Height of tuck loop lies between knit and miss loop, hence CPI value of Single Lacoste fabric lies between Weft Lock Knit and Single Jersey fabric. 


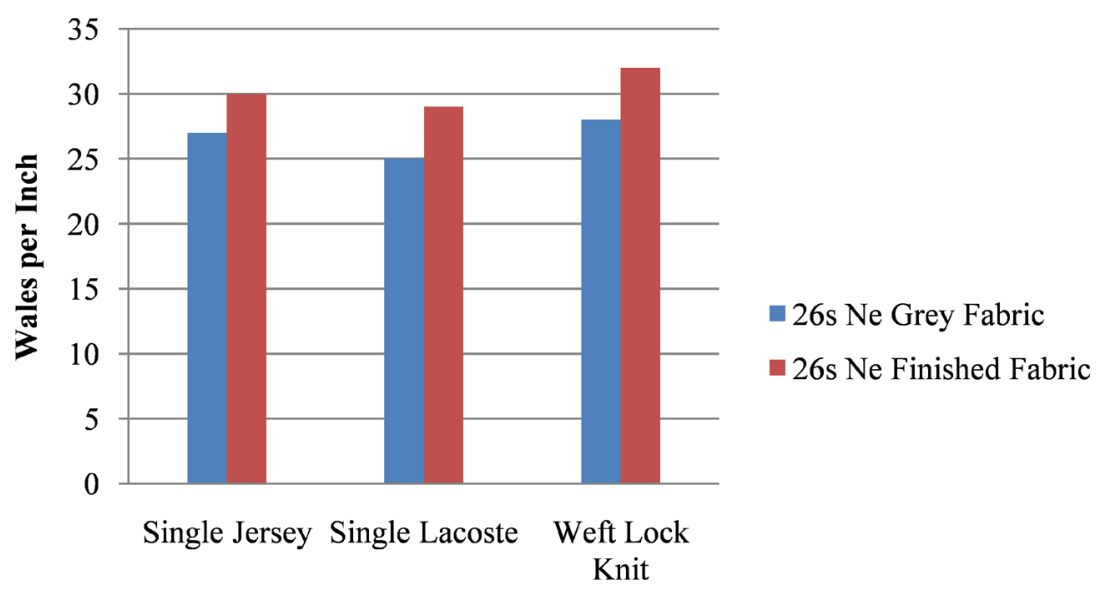

Yarn Count (Ne)

Figure 1. Comparison among Wales per Inch of the Structures for $26 \mathrm{Ne}$.

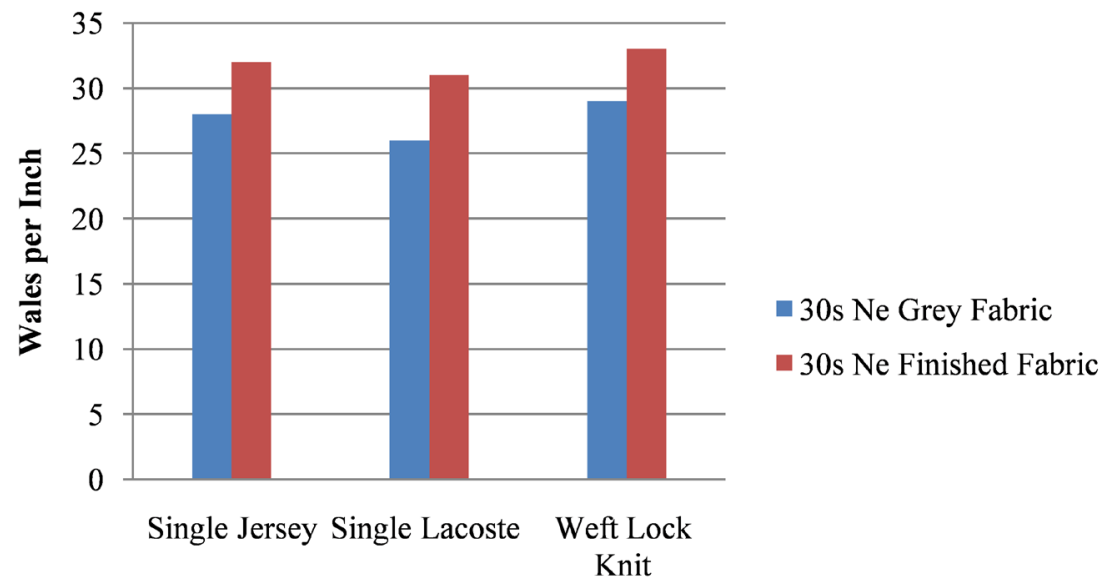

Yarn Count (Ne)

Figure 2. Comparison among wales per inch of the structures for $30 \mathrm{Ne}$.

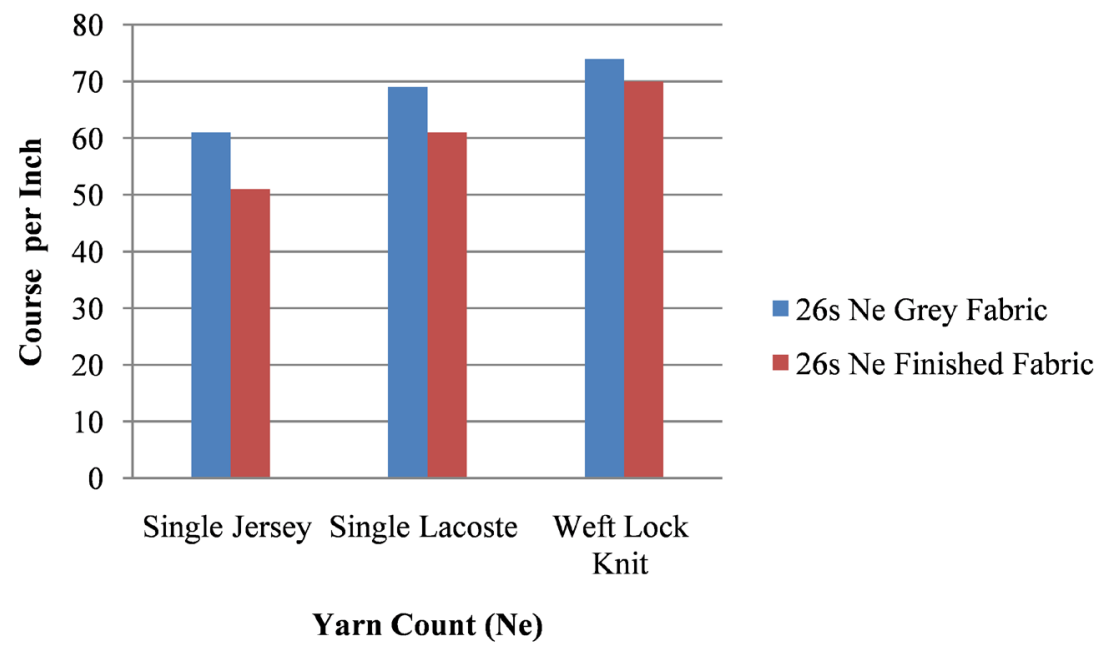

Figure 3. Comparison among course per inch of the structures for $26 \mathrm{Ne}$. 
During scouring and bleaching process fabric is circulated along the flow of liquor and some stress implies along the length of fabric. Hence the courses decrease in case of RFD fabric.

Here the CPI value of the fabric made of $30 \mathrm{~s} \mathrm{Ne}$ (both states) follows the previous sequence (Figure 4). But the values decreases due to finer yarn.

\subsection{Comparison among Width of the Structures}

From Figure 5 it is observed that, Single Lacoste is much more and Weft Lock Knit fabric is less wide. Because the structure with tuck loops is wider than with the knit loops and the loop shape has a wider base at loops. Again float loops makes the Weft lock Knit fabric narrower as there is no looped configuration and hence the whole structure is pulled to minimum width.

During scouring and bleaching process the fabric is circulated along the flow of liquor and some stress implies on the length of the fabric. Hence the width decreases in case of RFD fabric.

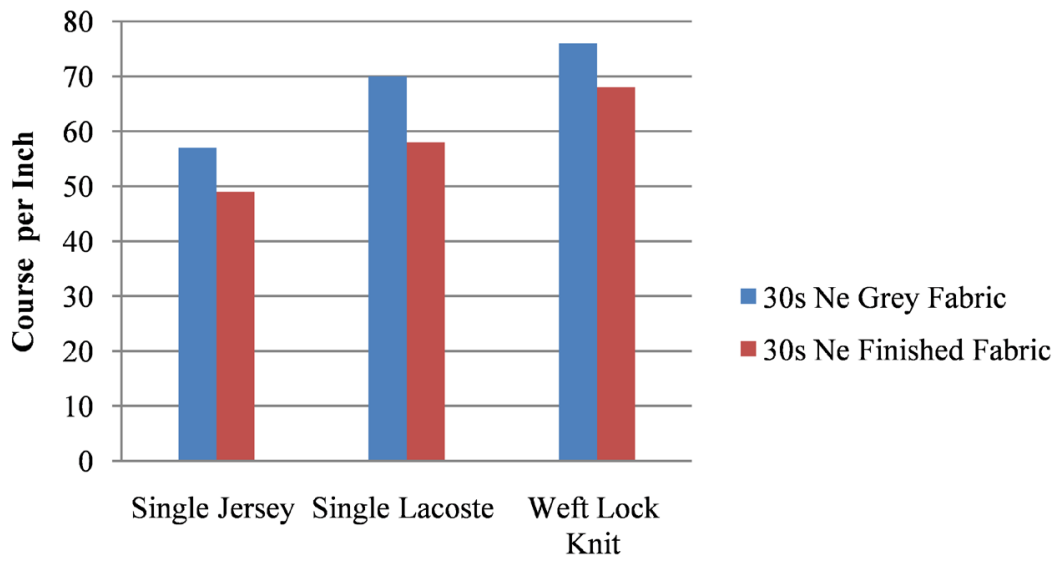

Yarn Count (Ne)

Figure 4. Comparison among course per inch of the structures for $30 \mathrm{Ne}$.

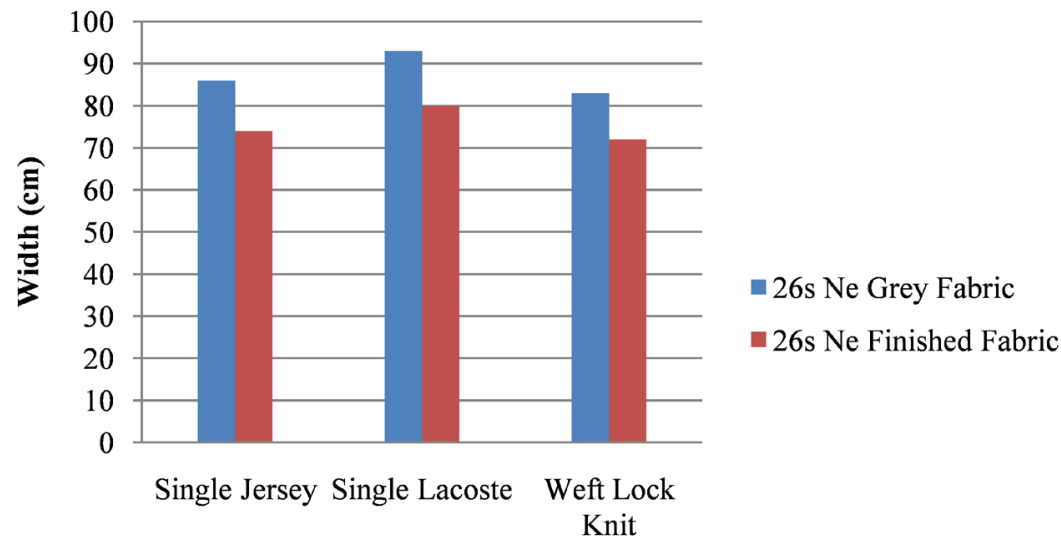

Yarn Count (Ne)

Figure 5. Comparison among width of the structures for $26 \mathrm{Ne}$. 
From Figure 6 it is clear that, the Width value of the fabrics made of $30 \mathrm{~s} \mathrm{Ne}$ count (both states) follows the previous sequence. But values decrease due to finer yarn.

\subsection{Comparison among Width Wise Shrinkage of the Structures}

According to the above Figure 7 Single Lacoste fabric has the highest widthwise shrinkage and Weft Lock Knit fabric has the minimum. Because, tuck loop tends to make the fabric wider and less extensible than knit stitches. Again miss loops tend to make the fabric narrower and highly extensible than knit loops.

After scouring and bleaching, the fabric has already shrinked. That is why shrinkage \% was lower at RFD state.

From Figure 8 it is very much observable that widthwise shrinkage (\%) of the fabrics made of $30 \mathrm{~s} \mathrm{Ne}$ (both states) follows previous sequence. But values decrease due to finer yarn.

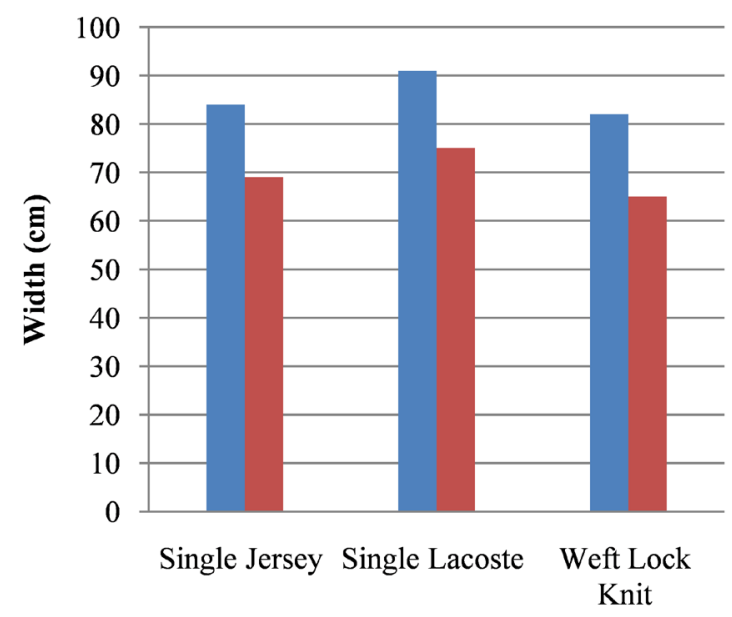

-30s Ne Grey Fabric

-30s Ne Finished Fabric

Yarn Count (Ne)

Figure 6. Comparison among width of the structures for $26 \mathrm{Ne}$.

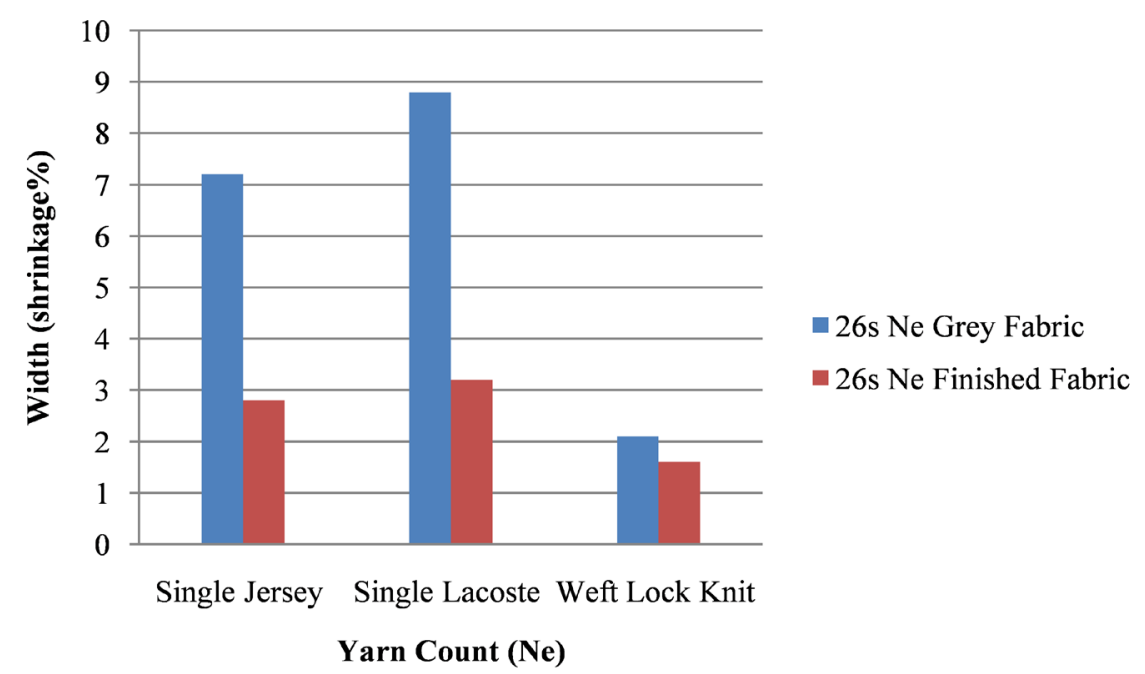

Figure 7. Comparison among width wise shrinkage of the structures for $26 \mathrm{Ne}$. 


\subsection{Comparison among GSM of the Structures}

From the Figure 9 it can be said that, Single Lacoste has the maximum GSM and Weft Lock Knit has got the minimum one. Reason behind that is fabric with tuck stitch is much thicker than knit stitch due to accumulation of higher amount of stitches at tucking places. Due to thick in nature the tuck stitched fabric is heavier in weight per unit area than the knit stitch. On the other hand float stitch is thinner than knit and tuck stitches. That's why Weft Lock knit structure has minimum GSM due to less yarn accumulation.

In case of RFD fabrics, due to shrinkage GSM increases in same manner.

From the Figure 10 it is clear that GSM of the fabric made of $30 \mathrm{~s} \mathrm{Ne}$ (both states) follows the previous sequence. But the value decreases due to finer yarn.

\section{Conclusion}

When machine diameter, stitch length and machine gauge are fixed, variation

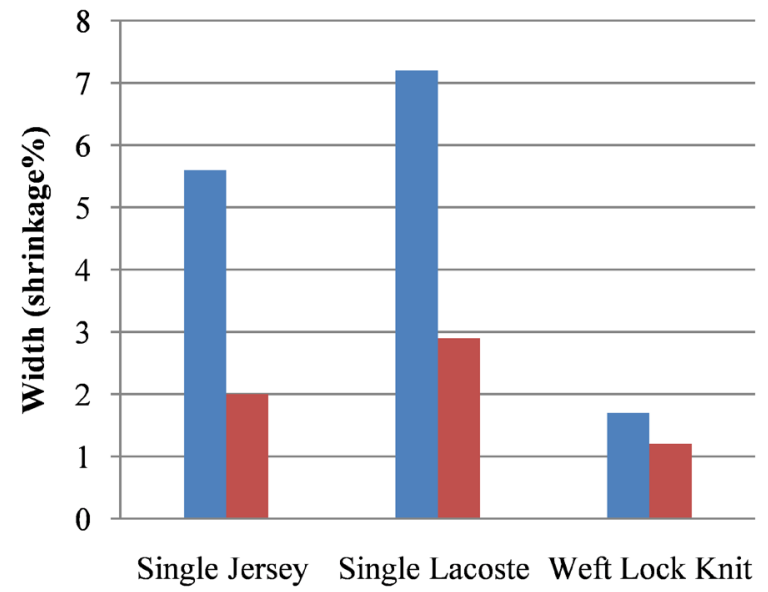

$\square$ 30s Ne Grey Fabric

- 30s Ne Finished Fabric

\section{Yarn Count (Ne)}

Figure 8. Comparison among width wise shrinkage of the structures for $30 \mathrm{Ne}$.

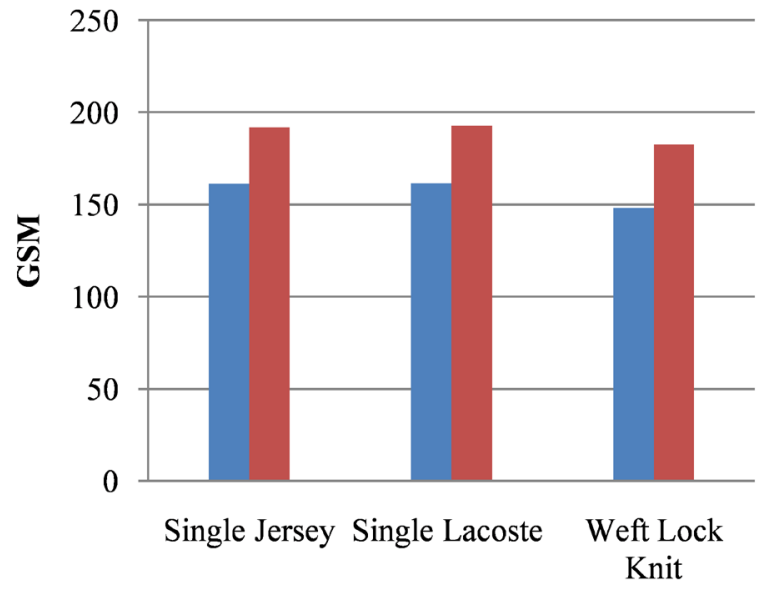

-26s Ne Grey Fabric

-26s Ne Finished Fabric

Yarn Count (Ne)

Figure 9. Comparison among GSM of the structures for $26 \mathrm{Ne}$. 


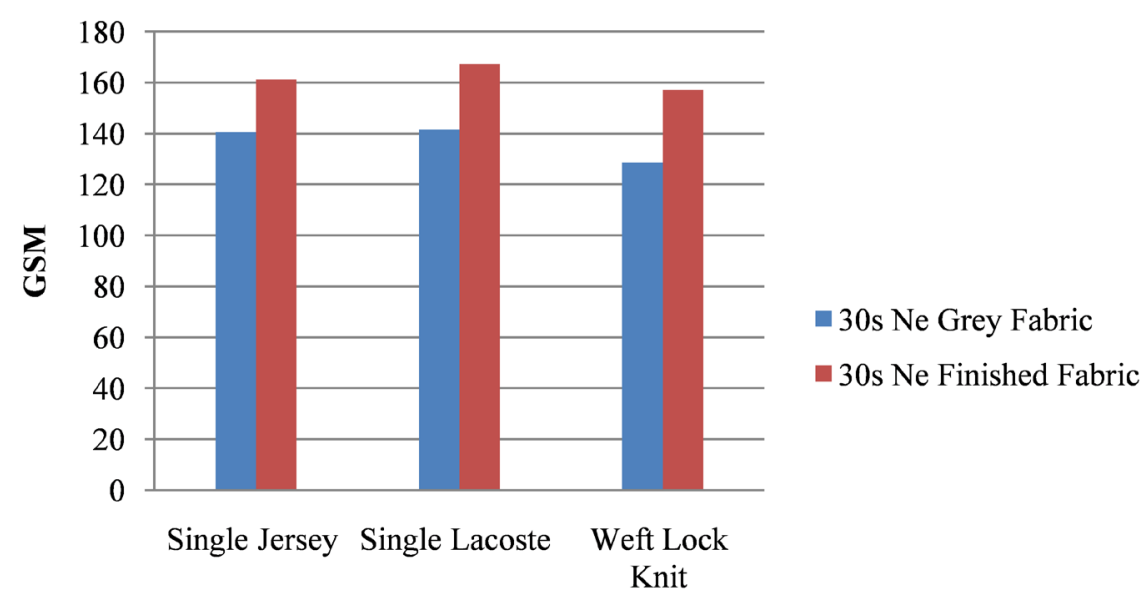

Yarn Count (Ne)

Figure 10. Comparison among GSM of the structures for $30 \mathrm{Ne}$.

comes in wales per inch, course per inch, fabric width, shrinkage properties, GSM of Single Jersey, Single Lacoste and Weft Lock knit fabrics. Here, GSM is an important parameter which has a vital impact on knitted fabric production. GSM is generally controlled by stitch length. But here different fabric structure and yarn count also affect GSM. This will be beneficial for further thesis of related knitting field.

\section{References}

[1] Shah, D.L. (2003) Latest Techniques of Processing Knit Fabrics Containing Elastomeric for Fashion Garments. Man-Made Textiles in India, 12, 3-8.

[2] Saufley, C.E. (1992) Continuous Finishing of Circular Knit Fabrics. AATCC Review, 24, 17-19.

[3] Desale, V., Raichurkar, P.P., Akhilesh, S. and Ramkesh, Y. (2008) A Study on Spirality of Single Jersey Knitted Fabric. Textile Journal, 4, 1371-1379.

[4] Bourah, R.K. (2004) Process Control in Circular Knitting Plant. Textile Committee, 2, 26-31.

[5] Tendulkar, S.R. and Kulkarni, G.N. (1994) Improved Methods of Hosiery Processing. Textile Dyer and Printer, 16, 25-29.

[6] Euscher, G. and Jayachandran, S. (1997) Knit Goods Processing. Indian Textile Journal, 4, 19-21.

[7] Gulzar, A.B. and Chris, M.C. (2014) A Study on Damage to PLA Knitted Fabrics during Scouring and Bleaching. Polish Journal of Chemical Technology, 16, 45.

[8] Lonati, E., Lonati, F. and Lonati, T. (2014) Knitting Machine, Particularly with High Gauge, with Improved Needle Actuation Cams. US Patent No. EP2758577A1.

[9] Pai, T.H. (2012) Circular Knitting Machine with a Fine Gauge. US Patent No. 8484998 B1.

[10] ASTM D3774-96 (2012) Standard Test Method for Width of Textile Fabric. American Society for Testing and Materials, West Conshohocken, PA, USA.

[11] ASTM D3776 (2013) Standard Test Methods for Mass per Unit Area (Weight) of 
Fabric. American Society for Testing and Materials, West Conshohocken, PA, USA.

[12] AATCC (2000) AATCC Test Method 135-2012, Dimensional Changes of Fabrics after Home Laundering. American Association of Textile Chemists and Colorists, Research Triangle Park, NC, USA. 